\title{
STEM Education: An Emerging Field of Inquiry
}

\author{
Richelle Marynowski \\ University of Lethbridge, Canada
}

The collection of articles in the book provides insight into what constitutes STEM education and practices that could be used to further STEM teaching and learning in K-12 programming and teacher education with a focus on the Australian context. The articles are arranged in an order that flows well from the larger picture and definition of STEM education and the reasoning behind the call for more focus on STEM in schools and pre-service teacher education, to specific examples of how to incorporate STEM into practice, ending with a consideration of the future possibilities. Each of the chapters is well written and provides theoretical and research bases for their arguments. Having read each of the chapters, I have a clearer sense of what constitutes STEM education and how I might go about incorporating the philosophy of STEM into practice at the K-12, pre-service teacher, and in-service teacher level.

The introduction by Barkatsas, Carr, and Cooper is clearly written and lays a compelling foundation for the need to spend more time and energy researching effective STEM education practices. The concern of declining enrolment in STEM fields and the growing need of innovators in the global marketplace is one that Barkatsas, Carr, and Cooper highlight and is revisited in several of the chapters throughout the volume. In addition, they note that "Educators at all levels are grappling with the complexities and issues that are emerging in what is a relatively new, and some might argue, ill-defined field" (p. 2). As such, this book begins with a chapter presenting a definition of STEM that highlights some of the complexities while offering a reconceptualization of the organization of teaching and schools to foster the development of both disciplinary knowledge and skills that transcend specific disciplines.

Fraser, Earle, and Fitzallen present a comprehensive historical overview of the development of STEM as a focus in both education and the evolving demands of the workforce. One compelling statement from the authors regarding why science, technology, engineering, and mathematics are placed together and focused upon is "while we need science and mathematics to understand the world around us, it is through engineering and technology that we interact with and mould it" (p. 11). This articulation by Fraser, Earle, and Fitzallen provides a way of thinking about how one might consider teaching in a STEM context. The authors also stated that "At the heart of the term STEM, therefore, is the supposition that there an inherent connectivity of the four disciplines that is well understood and that should lead to meaningful integrated STEM learning" (p. 11). The key to a rich STEM learning environment is leveraging the connectivity between the disciplines while not sacrificing what makes each discipline unique. However, the current structures in education do not allow for easy opportunities for teachers to connect the disciplines in a rich fashion.

\footnotetext{
${ }^{1}$ Contact: University of Lethbridge, 4401 University Drive Lethbridge, Alberta, T1K 3M4, Canada, Email: richelle.marynowski@uleth.ca Marynowski, R. (2019). STEM education: An emerging field of inquiry. Journal of Research in STEM Education, 5(1), 93-99.
} 
In order to achieve a connected learning experience for students, Fraser, Earle, and Fitzallen point to the role of teachers and disrupting current beliefs and practices with respect to the way science, technology, engineering, and mathematics exist within a school structure and the way that they are taught. In looking to future goals of STEM education, they state that the interdisciplinary nature of STEM "is more than achieving an increased understanding of its individual disciplines, rather it challenges teacher beliefs about their discipline or disciplines, how they interact, and are taught and learned and therefore, the pedagogies and practices that they adopt" (p. 23). The message that teachers are key to the successful implementation of integrated learning experiences for students is echoed in several chapters in this volume. As Fraser, Earle, and Fitzallen note, teacher professional development and initial teacher education need to support teachers in making pedagogical decisions that reflect the philosophy of STEM education. This introductory chapter sets a solid foundation for the rest of the chapters that then point to specific ways in which this goal can be achieved.

Chapter 2 by van Driel, Vossen, Henze and de Vries is a nice follow up to the first chapters as it presents a project in which the principles of STEM education that are highlighted in the first chapter can be integrated into a research and design course. This course is not discipline specific but integrates the disciplines. The goal is to highlight the work of professionals in the STEM disciplines, where "professionals in different disciplinary backgrounds work together in teams" to find an optimal solution to a problem where "there is never one correct answer" (p. 34). The focus on design principles and the opportunity for students to engage in current research and design challenges are fundamental to the success of such a program. Though this chapter does not report on research relating to the implementation of a research and design course, the description of how it was enacted in a specific context sends an encouraging and hopeful message that integrated STEM educational experiences are possible.

One element of prompting a focus on STEM education that several chapters refer to is the development of a 'pipeline' of training for students to enter STEM fields, which is specifically noted in Chapters 1, 2, 3, 4, 5, and 10. The notion that the purpose of STEM education is to funnel students into careers that use disciplines brings forth an image of students sliding down a tunnel and dropping into boxes from which they cannot escape. This was probably not the intent of the use of that description, however, regardless of the changes that are made to incorporate STEM principles into education systems, there is not enough known about what that impact might later have on careers in the future. As was noted in Chapter 3 by Jordan, a focus on STEM education in schools has decreased the performance and enrollment of students in mathematics and science specifically. Perhaps a focus on an integrated STEM approach in schools is turning students away from siloed learning in post-secondary. McLaughlin and Kennedy, in Chapter 12, commented that "learning and teaching in the science, technology, mathematics, and engineering disciplines often remains narrowly focused and content entrenched, especially in tertiary education" (p. 210). If students have an integrated set of learning experiences in school but then are faced with strict disciplinary knowledge in tertiary education, maybe this is then turning students away. Changes at all levels of education are key to sustaining change.

The positioning of STEM education in policy documents by Jordan in Chapter 3 through discourse analysis shows six themes that highlight the importance that these documents are placing on STEM education in Australia. The six themes are: STEM as a national enterprise; STEM as sustaining economic growth; STEM as maintaining prosperity; STEM as not being left behind; and STEM as declining. These themes show that STEM education is positioned in policy documents as "the means for Australia to maintain its economic advantage and for Australians to maintain their prosperous standard of living" (p. 58). Jordon comments that carefully reading policy is important "to understand both the vision being proposed and the roadmap presented to us to follow" (p. 46). She also cautions though that we "need to be mindful that official dominant discourses need to be tempered with the 
messy realities of use in schools" (p. 47). The vision being proposed of a pipeline of workers into STEM fields in order to maintain a level of prosperity is met with the realities of children, teachers, and school systems, which cause changes to the proposed roadmap.

While the first three chapters focus on STEM education in a holistic way, the next five chapters attend to specific content areas within STEM. Cooper and Thong's chapter on virtual reality is the first of the five. They offer a historical perspective on the evolution of immersive virtual realities and provide examples of how this technology could be used to support STEM education. Cooper and Thong discuss four elements of a "VR Education Model (VEM)" (p. 66, emphasis in original) that are important when considering the use of virtual reality in education. They are: "experiencing, engagement, equitability and everywhere" (p. 66, emphasis in original). Each of these elements are described and specific examples of how each of them could contribute to STEM education are included. The authors support the use of immersive virtual reality in STEM education in stating, "Preparing students to effectively navigate, contribute to and participate in virtual environments appears to be an important future set of STEM-related skills and knowledge" (p. 71). Though this chapter does not describe a specific research project exploring the VR Education model, the theoretical foundation is well laid out and the examples provided give the reader a sense of how one could leverage this technology in one's practice.

Chapters 5, 7, and 8 continue with a specific content area with each chapter describing research specific to mathematics. Chapter 5 by Siemon, Banks, and Prasad focuses on multiplicative thinking development and trajectories of student learning. While the focus is on mathematics specifically, Siemon, Banks, and Prasad lay a solid foundation as to the importance of mathematical thinking to each of the other STEM disciplines and why mathematics cannot be attended to when the need arises as students solve complex problems. They state that "If the mathematics is only considered 'in passing' as a 'means to an end', it is highly likely that the teaching focus will be procedural rather than conceptual and isolated and context-specific rather than connected and generalised" (p. 77). While the authors advocate for mathematics to be taught separately, they also recognize the importance of balance between discipline specific knowledge and "the opportunity to apply this knowledge in rich, integrated settings" (p. 79). Siemon, Banks, and Prasad report that targeted, assessment driven teaching can improve student performance on multiplicative thinking tasks through describing case studies of how the targeted teaching was implemented within two schools. Though the authors make an excellent case at the beginning of the chapter for the importance of mathematics learning in STEM, they do not come back to suggest how the targeted teaching would also support student performance in other STEM disciplines.

Prodromou and Laviscza present inquiry based learning in statistics and supporting teachers to use inquiry based practices in Chapter 7. The field of statistics is presented by the authors as "vital skills for not only prospective data users, but also for all citizens" (p. 118). As such, being able to make meaning from statistical data from STEM disciplines is an important aspect to consider in any STEM program. Prodromou and Laviscza report on the setting up of classroom norms that support inquiry based learning in statistics through engaging students in rich problems and the statistical inquiry cycle. Of the three chapters specifically on mathematics, this chapter presented ideas that were the most connected to the understanding of STEM that was presented in the first chapter.

While Chapters 5 and 7 focus on the teaching of mathematics, Chapter 8 highlights cultural values and the impact those values have on what students' value in mathematical learning. Jiang, Seah, Barkatsas, Ieong, and Cheong argue that values are often neglected in research but are needed to "sensitise researchers, academics and other societal milieu on the impact research has on society, our planet and the survival of our species" (p. 133). The authors describe valuing as the "process of attaching different levels of importance to different facets of mathematics pedagogy as they experience 
it" (p. 139). Jiang et al.'s exploration of Macau's students' responses to the international 'What I Find Important (WIFI)' survey highlights that Macau students value "achievement; relevance; practice; technology; communication and development" (p. 132, emphasis in original) in that order of importance. Similarly, to Chapter 5, the authors comment on the relevance of the study to STEM education at the beginning of the chapter, there is little follow-through throughout the chapter. While the information presented in the chapter is interesting and well written, the connection to STEM education is a bit lacking.

Chapter 6 aims to illustrate how adding the Arts to STEM to get STEAM specifically with pre-school aged children in a Reggio Emilia (RE) inspired program. Gilbert and Borgerding argue that in primary education and in an RE program, an integrated approach to learning is the dominant philosophy. They stated, "teachers in these contexts have a predisposition for integrated thinking and a willingness to trust in the thinking ability of young children" (p. 103). Gilbert and Borgerding describe the contribution that including the arts as a focus in STEM to create STEAM is "to best articulate the centrality of the arts as a means for children to express and engage with their thoughts regarding content in developmentally appropriate ways" (p. 104). They then present two ways in which the tenets of STEAM were integrated into exploring the concept of air as well as specific pedagogical insights in working with young children. Though Gilbert and Borgerding frame the arts as an important additional element to STEM, their description of STEAM does not clearly identify how their vision of STEAM is significantly different than what is being described by other authors as STEM. Expression of ideas, design, and communication are significant elements of STEM education, which includes "using the Arts, as they designed solutions and tasks concerning the phenomena" ( $p$. 115), which the authors argue is central to including the arts in the acronym. Additionally, the context for this project was a very specific and niche area of education and the integration of STEAM was presented as seamless. What would be helpful to have included in this volume is a description of a project at the secondary level where the disciplines are more siloed and fit less seamless into the STEM education philosophy. However, illustrating that STEAM learning can occur at the primary level is an important contribution.

Chapters 9, 10, and 11 each present ways in which pre-service teacher education can support beginning teachers with the integration of a STEM education philosophy while Chapter 12 articulates ways in which instructors at the tertiary level can be supported to do the same in their courses and programs. In Chapter 9, Nielson, Georgiou, Howard, and Forrester describe the pedagogical approaches that the teacher educators in the primary pre-service teacher educator program at the University of Wollongong in New South Wales utilize to support STEM education. They framed their work by articulating their vision of STEM education: "We broadly conceive STEM as an integrative view of learning where the individual disciplines provide context for explorations across fields" (p. 156). This articulation of their conception of STEM education is consistent with the beginning chapters in this volume. Nielson, Georgiou, Howard, and Forrester continue with examples of how the pre-service teacher education program is structured and approached in science, mathematics, and technology. They also describe how their program supports pre-service teachers in managing the "on-going curriculum change" (p. 164) so that students "have a broad view of the nature of knowledge" and are able to "respond to the constantly changing environment in which they will work" (p. 165). The authors offer concrete ways in which these goals could be achieved and are being achieved at their university.

Cooper and Carr's chapter continues the conversation on pre-service teacher education but focuses on, "How teachers conceptualise, interpret, and subsequently enact STEM education" (p. 170). They explore the psychosocial factors of attitudes, norms, and self-efficacy of pre-service teachers enrolled in an elective STEM education course through analyzing student responses to the question, "What is STEM education? How do you define it?" (p. 173, emphasis in original) and student respons- 
es to being asked to "visualise" their confidence to teach STEM" (p. 173). Cooper and Carr noted that pre-service teachers conceptualize STEM as an integrated approach to teaching that emphasizes developing problem-solving skills. Pre-service teachers also stated that they have a positive view of STEM education but low levels of self-efficacy to teach specifically engineering and technology. In light of those conceptions, Cooper and Carr offer considerations for pre-service teacher education programs to integrate into their STEM programs. The offerings by the authors are consistent with the framing of the beginning chapters around the discourse regarding STEM education in policy documents and include encouraging pre-service teachers to read and think about policy documents critically.

Chapter 11 focuses on the development of pre-service teacher STEM identity through engaging in a mentorship program for schoolgirls that was designed "to enhance girls' self-confidence and self-identify in STEM" (p. 194). Berry, McLaughlin, and Cooper argue that "STEM identity can develop progressively through working with expert mentors in authentic contexts" (p. 193). As such, the mentorship program they describe groups schoolgirls, pre-service teachers, teacher educators, and STEM technicians. The mentoring program itself provides a unique way to engage different groups in building STEM capacity in both the schoolgirls and the pre-service teachers. The results of the study suggest that a mentoring model can support the evolution of a pre-service teacher's STEM identity in a positive way.

McLaughlin and Kennedy follow with a description of a project, called the STEM Ecosystem project, at the tertiary level to develop the capacities of academic staff in developing cross-disciplinary STEM opportunities and pedagogies. The authors note that "efforts by STEM academics to undertake cross-disciplinary industry-based projects are rare and often not sustained" (p. 210). The intent of the Ecosystem project was to "create an ecosystem of interdependent networks and collaborative leadership frameworks" (p. 212) that would be able to be sustained beyond the end of the project. Two case studies were presented that illustrated how the two specific elements of the STEM Ecosystem project were successfully enacted: the development of a supportive host environment and the "nurturing and sustainability" (p. 215) of STEM academics as leaders. McLaughlin and Kennedy found that academic "staff were empowered by their involvement in the Ecosystem and the industry mentoring opportunities" (p. 218) and that this empowerment motivated change in themselves and others. The importance of enacting change at all levels of education is highlighted in this chapter that describes an effective way to inspire academic staff to embrace STEM education at the tertiary level.

Though the collection of chapters present success stories in STEM education, many challenges enacting a STEM curriculum or philosophy are also noted throughout this volume. Challenges as noted by the authors of different chapters fall under three main categories: systematic or structural; knowledge; and resources. Systematic challenges refer to the structure of school where content is taught and assessed in discrete disciplines. Fraser, Earle, and Fitzallen comment that "The extent to which the structure of schools and schooling act as impediments to authentic and engaging STEM education... is unknown" (p. 20). This also relates to the structure of pre-service teacher education where, in many instances, pre-service teacher programs are focused on a specific discipline rather than STEM as an integrated discipline. Other systematic issues were the prevalence of large scale testing also focusing on discipline specific knowledge rather than integrated or general skills.

Knowledge challenges relate to teacher knowledge (in-service and pre-service), public knowledge, and the sharing of knowledge. Cooper and Thong point to the need for in-service teacher professional development in order for teachers to be able to feel comfortable integrating virtual and mixes reality systems into their teaching. Additionally, three of the chapters focus specifically on pre-service teacher programs (Chapters 9, 10,11) and the role they play in developing teachers that are confident to teach STEM. Public knowledge and the sharing of knowledge are the discourse 
that surrounds STEM education and the availability of knowledge that can be and is shared between groups to leverage research and projects that have been conducted. Jordan in her discourse analysis of policy documents clearly illustrates a message that is "future oriented" (p. 58), "determinist" with a "fear of falling behind" and a "sense of urgency" (p. 58). These are accompanied by a "simplistic" view where complexities are "downplayed or ignored" (p. 59). A clear sense is given that if we just did A, B would most certainly follow.

Resources is the third category of challenges that are most prevalently noted by authors. These connect to financial resources to both purchase equipment that would support engaging students in worthwhile tasks and to support teacher professional learning. Additionally, resources for teachers to access that include people that are currently engaged working in STEM related fields and tasks themselves. As noted in Chapter 2 by van Driel, Vossen, Henze, and de Vries, "Many teachers have never worked outside of a school. Connecting with local STEM industries will help them to understand the realities of STEM professionals and broaden and inspire their view of STEM education" ( $p$. 40). Though each of these challenges can be considered separately, they are connected, much like the STEM disciplines. Systematic challenges are perpetuated by a lack of knowledge or a lack of resources, and a knowledge regarding STEM fields, pedagogy, and the importance of STEM.

With respect to the specific disciplines that this volume attends to seven of the 13 chapters specifically connect to STEM as an integrated approach to education while the remaining six chapters address specific disciplines within STEM. As noted earlier, three chapters in this volume are specifically connected to mathematics. There is one chapter specifically on technology (Chapter 4), one chapter advocating for the arts to be integrated (Chapter 6). Science is peripherally addressed in Chapter 9 along with mathematics and technology. Interestingly, the collection decidedly lacks a focus on engineering. Nielson et al. comment that "we need to do more to deliberately incorporate engineering" (p. 164). This is followed by Cooper and Carr in Chapter 10 who note that "an overwhelming majority of PSTs reported not feeling confident to teach engineering related concepts" (p. 183). Even though authors in this volume note the need for support integrating engineering concepts and practices into STEM education, unfortunately this volume provides little to add to the understanding of how engineering concepts can be specifically integrated.

The final chapter, or epilogue, by Hobbs provides a glimpse into future possibilities of STEM education and provides an excellent overview of how each education partner can contribute to forwarding a focus on STEM. Hobbs also provides a vision for STEM education that includes five principles that initial teacher preparation, early childhood education, school education, and tertiary education can work together on. The five principles are: normalize STEM as an essential component of education; the normalization must be deliberate, explicit, and practiced; there is no one "way to do, learn or represent STEM" (p. 227); collaboration between and within disciplines and education partners is prevalent; and one's efforts to incorporate STEM principles are to be documented and shared. These five principles provide an outline for ways in which interested stakeholders can work together to improve STEM education at all levels.

Overall this volume is rich in ideas that inspire the reader to rethink not only practices in STEM education, but all education. Despite the challenges that are noted throughout the chapters, the collection provides a sense of hope and excitement regarding the potential that a focus on an integrated STEM education could provide learners at all levels. Considering integrative experiences for students that highlight connections between and among disciplines serves to broaden learning beyond disciplinary knowledge but also honoring that knowledge. STEM education is an opening and widening of possibilities not a funneling or narrowing. This volume addresses four levels of education: primary, secondary, tertiary, and teacher education (pre-service and in-service) as well as incorporates research completed in four different countries: Australia, Macau, Netherlands, and North America. 
Barkatsas, Carr, and Cooper have developed a thoughtful resource for those who are beginning in their STEM education journey or are looking for different ways to incorporate STEM principles into an existing program.

\section{References}

Barkatsas, T., Carr, N., \& Cooper, G. (Eds.). (2018). STEM education: An emerging field of inquiry. Leiden, Netherlands: Koninklijke Brill NV. 